\title{
Facile Synthesis of Graphene Oxide/Titanate Nanotube Composites and Their Application for Cobalt(II) Removal
}

\author{
Min-Da Xu, ${ }^{1,2}$ Zhen Jin ${ }^{\mathbb{D}},{ }^{1,2}$ Wen-Jie Xie, ${ }^{1}$ De-Cai Wang, ${ }^{1,2}$ Guang-Song Xu, ${ }^{3}$ \\ Ai-Jing Wang, ${ }^{1,2}$ Ran Zhang $\mathbb{D}^{4}{ }^{4}$ and Jian Huang $\mathbb{D}^{3}$ \\ ${ }^{1}$ School of Materials and Chemical Engineering, Anhui Jianzhu University, Hefei, Anhui 230601, China \\ ${ }^{2}$ Key Laboratory of Functional Molecule Design and Interface Process, Anhui Jianzhu University, Hefei, Anhui 230022, China \\ ${ }^{3}$ School of Environment and Energy Engineering, Anhui Jianzhu University, Hefei, Anhui 230601, China \\ ${ }^{4}$ Research Institute of Wood Industry, Chinese Academy of Forestry, Beijing 100091, China \\ Correspondence should be addressed to Zhen Jin; ftbjin@hotmail.com, Ran Zhang; zhangran_caf@163.com, and Jian Huang; \\ 117947453@qq.com
}

Received 1 November 2021; Accepted 30 December 2021; Published 28 January 2022

Academic Editor: Da-Ren Hang

Copyright (c) $2022 \mathrm{Min}-\mathrm{Da} \mathrm{Xu}$ et al. This is an open access article distributed under the Creative Commons Attribution License, which permits unrestricted use, distribution, and reproduction in any medium, provided the original work is properly cited.

\begin{abstract}
In this work, the novel graphene oxide/titanate nanotubes (GTNT) composites were synthesized through a facile and high-yield alkaline hydrothermal method. SEM, TEM, XRD, BET, and TGA/DTA were applied to study the morphology and structure of the GTNT composites. The results show that a huge number of titanate nanotubes are closely attached to the graphene sheet structure and overlap each other. This hierarchical morphology endows the GTNT composites with not only the high specific surface area of $236.9 \mathrm{~m}^{2} / \mathrm{g}$ but also abundant porous structure, both of which are benefit for $\mathrm{Co}$ (II) adsorption. The batch adsorption experiments demonstrate that the GTNT composites have a high adsorption capacity and rapid kinetics for Co(II) adsorption (10 min for equilibrium). The adsorption capacity of the GTNT composites reaches $211.1 \mathrm{mg} / \mathrm{g}$. The adsorption kinetics of the GTNT composites fits well to the pseudo-second-order model, while the adsorption isotherm of which fits well to the Langmuir model. The adsorption performance of $\mathrm{Co}(\mathrm{II})$ ions on the GTNT composites has a great relationship with the $\mathrm{pH}$ value, in the $\mathrm{pH}$ range of $1-7$, the Co(II) adsorption capacity of the GTNT composites greatly increases with the increase of the pH value. In addition, the effect of coexisting anions on fluoride removal is also investigated. $\mathrm{Na}^{+}, \mathrm{K}^{+}$, and $\mathrm{Mg}^{2+}$ ions have shown a negligible effect on the $\mathrm{Co}$ (II) adsorption efficiency of the GTNT composites. However, the existences of $\mathrm{Cu}^{2+}, \mathrm{Cd}^{2+}$, and $\mathrm{Pb}^{2+}$ ions would clearly have an effect on the $\mathrm{Co}(\mathrm{II})$ adsorption of the GTNT composites. The adsorption mechanism is also discussed. It is believed that the GTNT composites can be considered as a potential functional material for removing the radioactive metals containing wastewater.
\end{abstract}

\section{Introduction}

During the last decade, rational disposal and management of the radioactive species have drawn great attention because a large amount of radioactive species has been discharged through unexpected nuclear power plant incidents [1-3]. Among various radioactive elements, ${ }^{60} \mathrm{Co}$ is widely used in radiotherapy, industrial radiography, sterilization, density measurements, and electroplating [4-6]. ${ }^{60} \mathrm{Co}$ also can be found in nuclear wastewaters as a result of the neutron bombardment of stable cobalt isotopes in the metal structures of nuclear power plants $[7,8]$. Upon exposure, skin burns, liver/kidney/bone cancers, and acute radiation sickness leading to death (EPA) can occur [9]. Hence, its stringent reduction to permissible levels in water should be performed.

Various technologies have been developed to purify the $\mathrm{Co}$ (II) ions contaminated with wastewater, such as precipitation [10], membrane separation [11], electrolysis [12], and adsorption [13]. It is well-accepted that adsorption is the wide-used $\mathrm{Co}(\mathrm{II})$ ions removal method due to the advantages of low cost, high flexibility, and easy operation [14]. However, most traditional adsorbents, such as active carbon [15], diatomite [16], and clay [17], often suffer from the low 
adsorption ability towards Co(II) ions. Thus, developing novel $\mathrm{Co}(\mathrm{II})$ adsorbents with high performance is still a big challenge.

Recently, titanate nanomaterials are widely studied as the promising adsorbent for metal ions removal [18]. Due to the great number of the exchangeable $\mathrm{Na}^{+} / \mathrm{H}^{+}$within the stable layers, titanate nanomaterials exhibit large adsorption performance to the heavy metal ions [19]. However, due to the small size, the further application of those titanate nanoadsorbents is still limited by the weak mechanical strength, strong tendency to agglomerate, and difficulty in separation. Graphene oxide (GO) is another well-studied adsorbent $[20,21]$. Owning to its large surface areas and oxygenated functional groups, GO and its derivatives are of great interest in fabricating hybrid adsorption. Many GObased nanoadsorbents with superior adsorption performances have been synthesized for water purification, such as $\mathrm{TiO}_{2} / \mathrm{GO}, \mathrm{Ag} / \mathrm{GO}$, and $\mathrm{Fe}_{3} \mathrm{O}_{4} / \mathrm{GO}[6,22,23]$. Although titanate and GO nanomaterials have been extensively studied for the adsorption of heavy metal ions from aqueous solutions, the reports mentioned that the titanate and GO hybrid nanoabsorbents for radioactive elements removal are still limited. In this work, the titanate nanotube/graphene oxide nanocomposites have been synthesized through a facile hydrothermal method, and their adsorption performance towards $\mathrm{Co}(\mathrm{II})$ ions also has been studied. In the composites, the titanate nanotubes are closely attached to the graphene sheet structure and overlap each other. This hierarchical morphology endows the GTNT composites with not only the high specific surface area of $236.9 \mathrm{~m}^{2} / \mathrm{g}$ but also abundant porous structure, both of which are benefits for Co(II) adsorption. The adsorption capacity of the GTNT composites reaches $211.1 \mathrm{mg} / \mathrm{g}$. It is believed that the superior adsorption capacity of the GTNT composites makes it a potential candidate for radioactive wastewater treatment in future practical application.

\section{Experimental}

2.1. Synthesis. All reagents were commercially available from Sinopharm Chemical Reagent Co., Ltd. (China) with analytical grade and were used without further purification.

GO was synthesized through the improved Hummers method. Typically, $1 \mathrm{~g}$ of graphite flake, $1 \mathrm{~g}$ of $\mathrm{NaNO}_{3}$, and $45 \mathrm{~mL}$ of $98 \%$ sulfuric acid were added into a $500 \mathrm{~mL}$ flask, and $6 \mathrm{~g}$ of $\mathrm{KMnO}_{4}$ was slowly added under the ice bath. The mixture was stirred for 2 hours. Then, the flask was heated to $60^{\circ} \mathrm{C}$ and stirred for 2 hours. Next, $200 \mathrm{~mL}$ of deionized water was added into the reactant and stirred at $90^{\circ} \mathrm{C}$ for 5 hours. Finally, $10 \mathrm{~mL}$ of $30 \%$ hydrogen peroxide was added into the flask. The obtained solution was filtered and washed with $5 \%$ hydrochloric acid solution and deionized water for 5 times. After ultrasonic treatment for 2 hours, GO can be obtained.

Next, $40 \mathrm{mg}$ graphene oxide, $2 \mathrm{~g}$ P25 powder, and $32 \mathrm{~g}$ $\mathrm{NaOH}$ were added into $80 \mathrm{~mL}$ deionized water, stirred $30 \mathrm{~min}$, and then transferred to an autoclave. Put the autoclave into the oven, set the temperature to $200^{\circ} \mathrm{C}$, and keep for 12 hours. The product was washed with dilute acid and ethanol and then dried in a vacuum oven at $60^{\circ} \mathrm{C}$ for 12 hours. In this way, the titanate nanotube/GO composites can be obtained.

2.2. Characterization. The morphologies and structures of the samples were examined by field emission scanning electron microscopy (FE-SEM; FEI Sirion-200), high-resolution transmission electron microscopy (HRTEM; JEM2010), and X-ray diffraction (XRD, Philips X'pert PRO) with $\mathrm{Cu}$ Ka radiation. The specific surface area and gas adsorption isotherms of the products were tested on a Coulter Omnisorp 100CX Brunauer-Emmett-Teller (BET). The concentration of the $\mathrm{Co}(\mathrm{II})$ ions was measured using the atomic fluorescence spectrometer (TAS-990).

2.3. Adsorption Experiments. The sorption of $\mathrm{Co}(\mathrm{II})$ ions on the titanate nanotube/GO composites was studied using the batch technique. The adsorption experiments were carried out in $15 \mathrm{~mL}$ polypropylene flasks containing $10 \mathrm{mg}$ of adsorbent and $10 \mathrm{~mL}$ of $\mathrm{Co}$ (II) solution with various concentration, and then, the flasks were shaken at $150 \mathrm{rpm}$ in a shaker at $25^{\circ} \mathrm{C}$ for $24 \mathrm{~h}$. The $\mathrm{pH}$ value was adjusted using negligible volumes of $\mathrm{HCl}$ and/or $\mathrm{NaOH}$.

After the adsorption experiments, the adsorbent was separated from the solution by centrifugation, and the residual $\mathrm{Co}$ (II) concentration in solution was measured by ICP. The residual adsorbents were centrifuged, washed with water, and dried in the oven at $60^{\circ} \mathrm{C}$.

In the kinetics study, the initial $\mathrm{Co}(\mathrm{II})$ concentration was $20 \mathrm{mg} / \mathrm{L}$, the adsorbents dose was $1.0 \mathrm{mg} / \mathrm{L}$, and the total suspension volume was $100 \mathrm{~mL}$. The samples were placed on a shaker for stirring. At predetermined time intervals, stirring were interrupted, while $6 \mathrm{~mL}$ of supernatant solutions was pipetted and centrifuged for the determination of the remaining $\mathrm{Co}(\mathrm{II})$ concentrations. In this case, the centrifugal speed was $5000 \mathrm{rpm}$.

The amount of $\mathrm{Co}(\mathrm{II})$ adsorbed on the adsorbents was calculated from the initial concentration $\left(C_{0}\right)$ and the final concentration $\left(C_{e}\right)$. The adsorption percentage (\%) was calculated as

$$
\text { Adsorption percentage }(\%)=\frac{\left(C_{0}-C_{e}\right)}{C_{0}} * 100 \% \text {. }
$$

The zeta potential test was carried out at Malvern Zetasizer Nano ZS90. Typically, GTNT composites were first ultrasonic dispersed in water. Then, almost $3 \mathrm{~mL}$ of the suspension was injected into the test cell. After test, the $\zeta$ potential of the GTNT composites can be obtained.

\section{Results and Discussion}

3.1. Characterization of the GTNT Composites. Figure 1 is a SEM photograph of the GO/titanate nanotubes composites (GTNT) obtained by the hydrothermal method. As shown in Figures 1(a) and 1(b), titanate nanotubes and graphene are intertwined to form a loose composite structure. Figure 1(c) shows the edge of a GTNT cluster, where the flake structure and curly edge of GO can be seen clearly. Figure 1(d) shows 


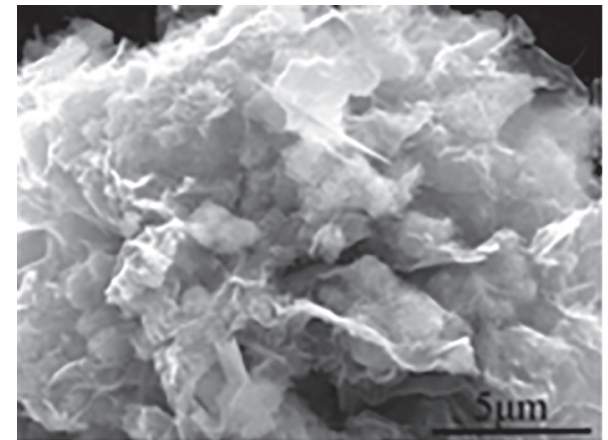

(a)

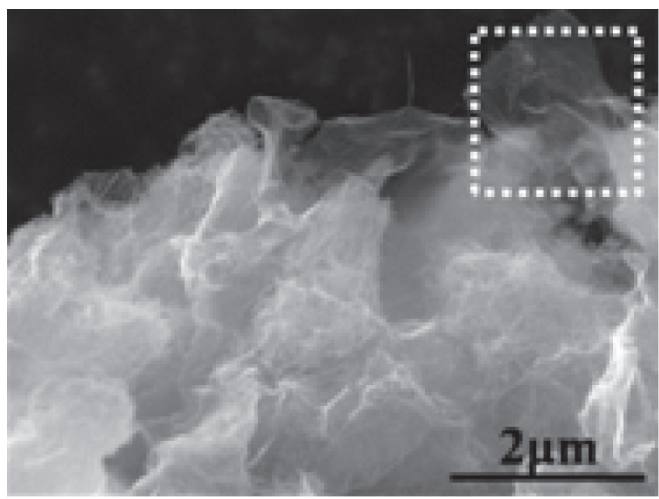

(c)

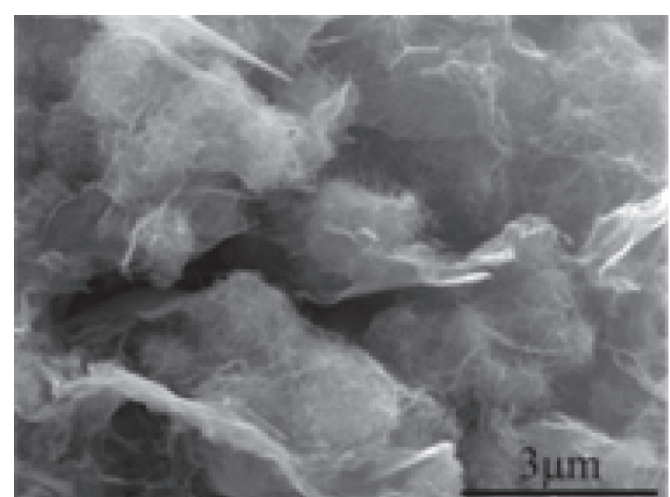

(b)

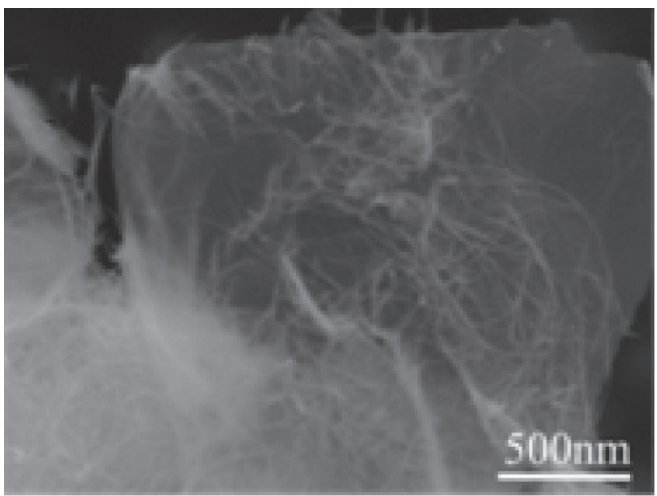

(d)

FIGURE 1: (a)-(c) The SEM images of the GTNT composites with different multiples. (d) The enlarged SEM images of the white box in (c).

the enlarged view of the white box in Figure 1(c), in which the modification of titanate nanotubes on GO nanosheet can be clearly seen. Moreover, the titanate nanotubes not only modify on the surface of GO nanosheet but also exist between the layers of graphene. For further characterization, the structure of the GTNT composites is also investigates by TEM, and the results are shown in Figure 2. Figure 2(a) shows the low-magnification TEM image of the GO/titanate nanotubes composites. It can be seen that a huge number of titanate nanotubes are closely attached to the graphene sheet structure and overlap each other. From the magnified TEM images (Figures 2(b) and 2(c)), the nanotube structure of titanate can be confirmed. At the edge of the individual GO nanosheet, the uncovered graphene and the titanate nanotubes protruding from the edge are clearly visible. This result is well consistent with that obtained by SEM. Figure 2(d) shows the high-resolution TEM image of the GTNT composite. From which, it can be seen that the titanate nanotubes with a multiwall structure and a length of several hundreds of nanometers can be characterized, indicating that those nanotubes are formed by the bending of (100) plane titanate nanosheets. The smooth and ultrathin GO nanosheet also can be observed.

Figure 3 shows the XRD pattern of GTNT composites. Those diffraction peaks located at $24.1^{\circ}, 28.1^{\circ}, 48.1^{\circ}$, and $60.6^{\circ}$ can be indexed to (220), (310), (331), and (521) planes of the $\mathrm{Na}_{0.5} \mathrm{TiO}_{2} \mathrm{O}_{4}$ (JCPDS 80-1282). To further investigate the thermal behavior of GTNT composites, TGA/DTA measurement was conducted and is shown in Figure 4. The TGA curve shows weight loss of about $17.3 \%$ from $50^{\circ} \mathrm{C}$ to $600^{\circ} \mathrm{C}$, and the corresponding DTA curve displays two endothermic peaks at about $80^{\circ} \mathrm{C}$ and $500^{\circ} \mathrm{C}$. The DTA curve does not show any exothermic peak, which indicates that the product is pure crystalline phase without any other amorphous phase. The weight percentage loss at $150^{\circ} \mathrm{C}$ is about $10.3 \%$, which is probably due to the removal of water molecules bound to the surfaces of the sample. The second peak at about $500^{\circ} \mathrm{C}$ is weight loss of $5.1 \%$, which is probably due to the removal of water molecules confined in the interlayer spaces of the GTNT composites during the increase in temperature. The remaining weight loss of $2.2 \%$ up to at $600^{\circ} \mathrm{C}$ is probably due to the oxidation of carbon.

In order to better understand the formation process of the GTNT composites, the influence of reaction time on the morphology of the sample was studied. As shown in Figures 5(a) and 5(b), when the reaction proceeds to $2 \mathrm{~h}$, P25 powders have been adsorbed on the GO nanosheets and the morphology of which remain granular structure. When the reaction proceeds for $6 \mathrm{~h}$ (Figures $5(\mathrm{c})$ and 5(d)), no particles can be seen, and some fine banded structures can be found on the surface of lamella of GO. When the reaction time reaches $12 \mathrm{~h}$ (Figure 5(e)), a large number of tubular structures can be seen on the surface of GO nanosheets; however, some unclosed strip structures (Figure 5(f)) still can be found. When the reaction time reaches $24 \mathrm{~h}$ (Figures $5(\mathrm{~g})$ and $5(\mathrm{~h})$ ), it can be found that 


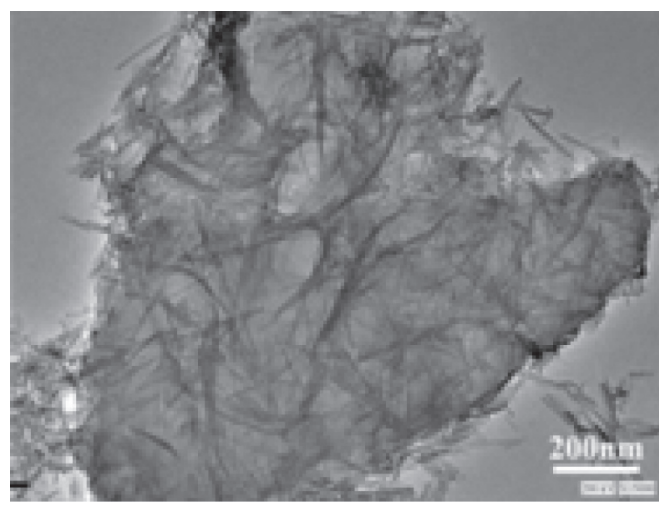

(a)

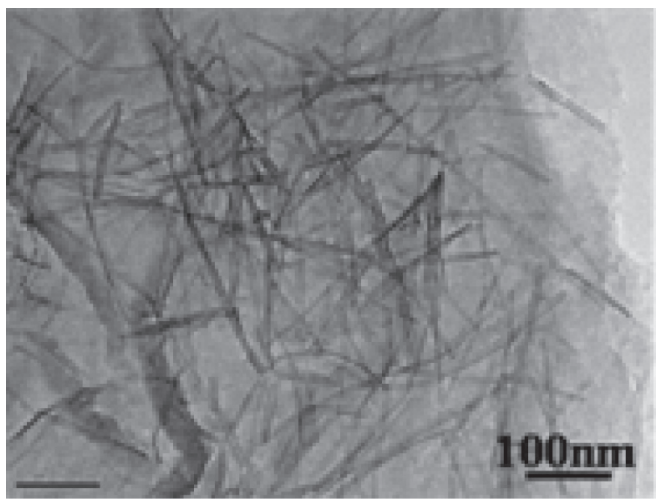

(c)

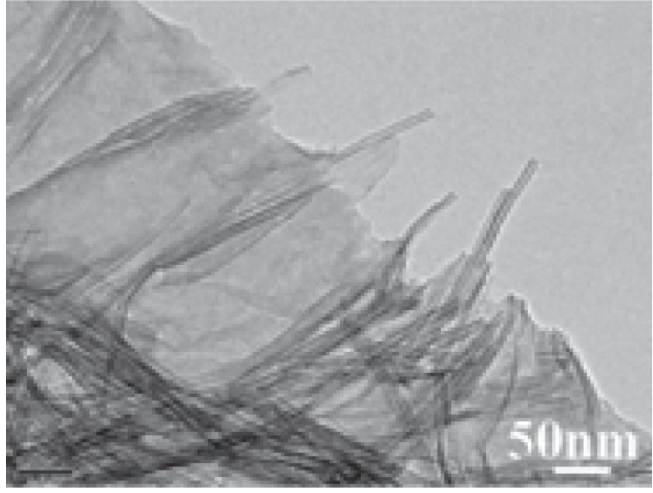

(b)

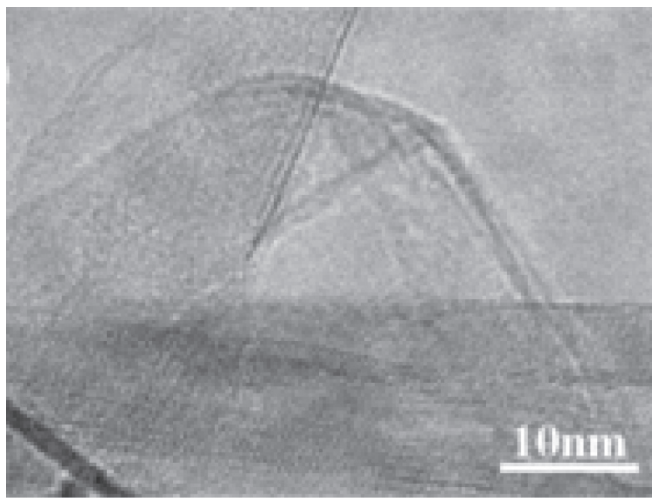

(d)

Figure 2: (a) The low-magnification TEM image of GTNT composite. (b)-(c) The enlarged TEM images of the GTNT composite. (d) The high-resolution TEM image of the GTNT composite.

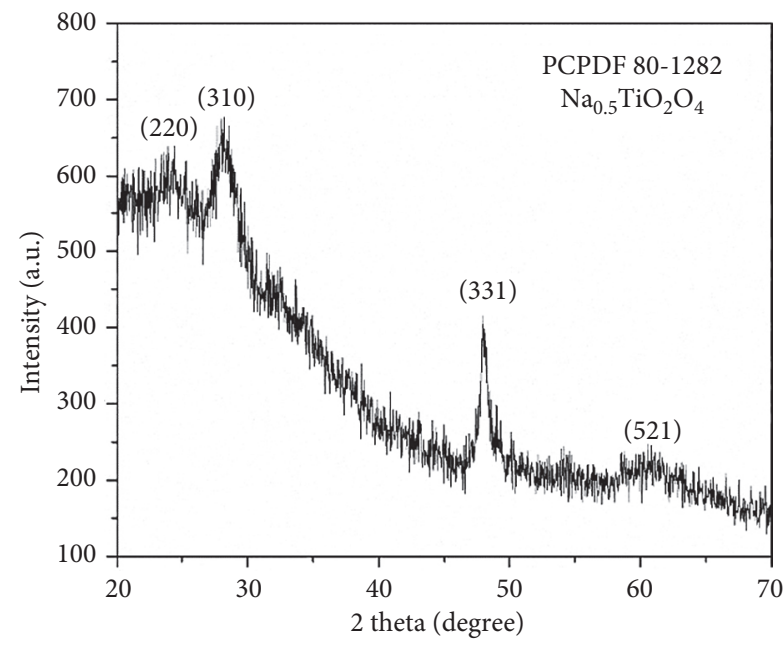

FIGURE 3: The XRD pattern of the GTNT composites.

the composites of titanate nanotubes and GO nanosheets are completely formed. In addition, the effect of $\mathrm{NaOH}$ concentration on the morphology of the samples also has been studied. Figure 6(a) shows the morphology of the sample synthesized without $\mathrm{NaOH}$. After $24 \mathrm{~h}$ reaction, P25 has been completely modified to the surface of graphene. However, the granular structure of the nanoparticle does not change. When the concentration of

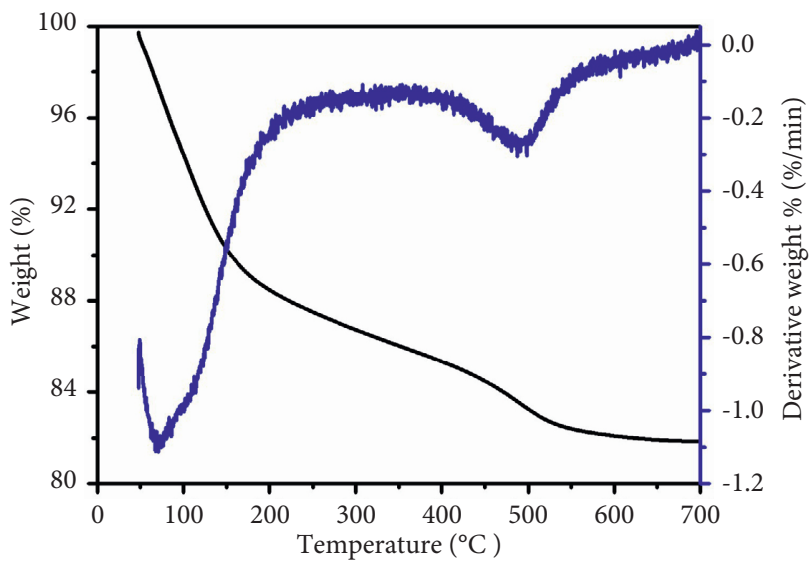

FIgURE 4: TGA curve and DTA curve of the GTNT composites.

$\mathrm{NaOH}$ increased to $0.1 \mathrm{M}$, the obtained samples remain the composite of $\mathrm{GO}$ nanosheets and nanoparticles (Figure 6(b)). Continue to increase the $\mathrm{NaOH}$ concentration to $1 \mathrm{M}$; some products with nanoplate-like structure can be observed (Figure 6(c)). When the concentration of $\mathrm{NaOH}$ reaches $4 \mathrm{M}$, on the surface of $\mathrm{GO}$ nanosheets, the structures of modified materials totally change to nanotubes (Figure $6(\mathrm{~d})$ ). As the reaction continued, the strong alkali condition would destroy the octahedral crystal structure of adsorbed $\mathrm{TiO}_{2}$ 

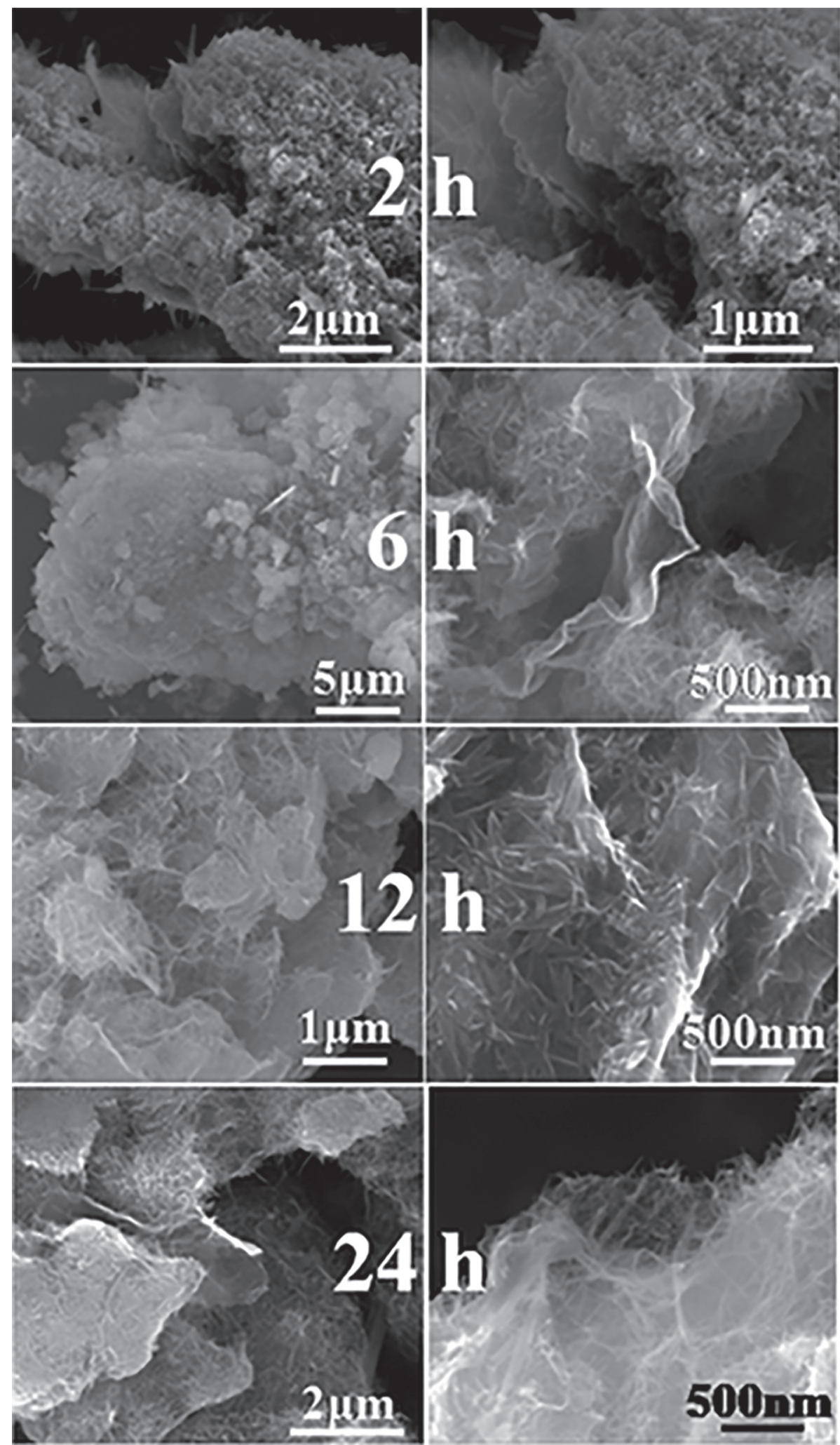

FIGURE 5: The SEM images of the samples obtained at different reaction times. (a)-(b) $2 \mathrm{~h}$. (c)-(d) $6 \mathrm{~h}$. (e)-(f) $12 \mathrm{~h}$. (g)-(h) $24 \mathrm{~h}$.

nanoparticles. The free $\left[\mathrm{TiO}_{6}\right]$ octahedron would bond together by $\mathrm{OH}$ bonds formed between titanium ions, which result in its growth along the (100) direction, and form a two-dimensional crystal layered structure on the GO surface
[24]. In order to saturate the dangling bond and reduce the surface energy, those nanolayers would roll up and finally formed the titanate nanotubes/GO composites. 


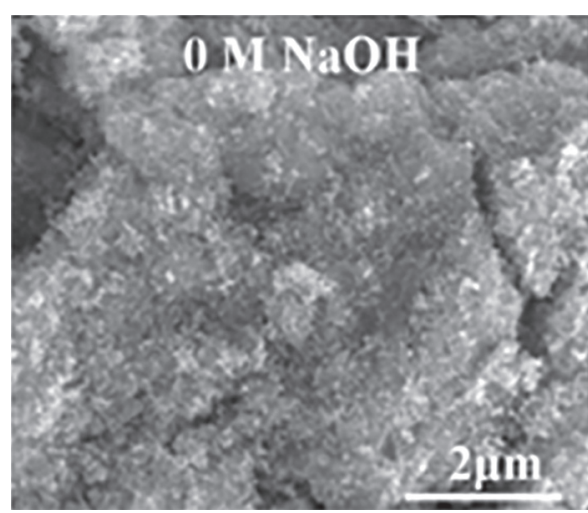

(a)

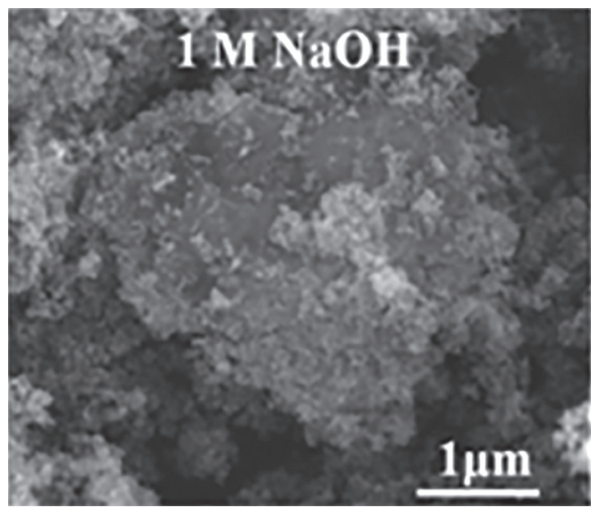

(c)

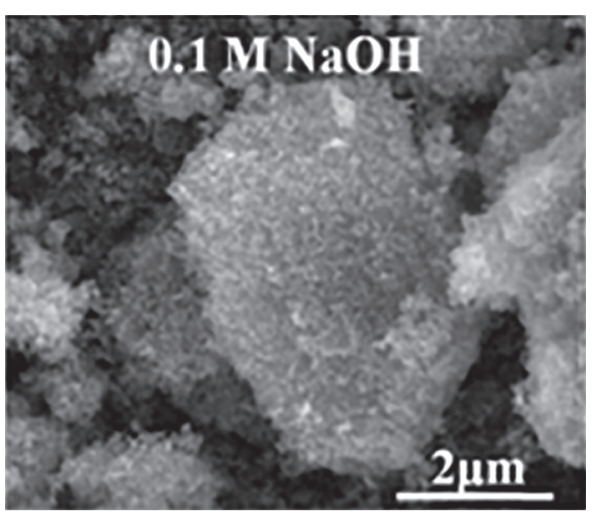

(b)

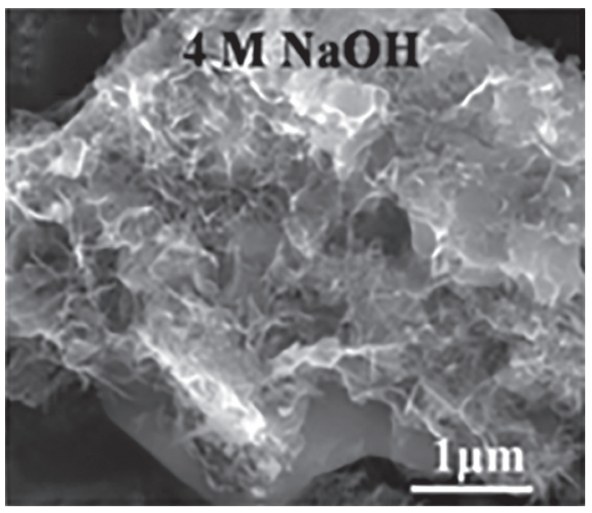

(d)

Figure 6: Effect of $\mathrm{NaOH}$ concentration on the morphology of the samples. (a) $0 \mathrm{M}$. (b) $0.1 \mathrm{M}$. (c) $1 \mathrm{M}$. (d) $4 \mathrm{M}$.

$\mathrm{N}_{2}$ adsorption/desorption isotherms are also employed to examine the microstructure of the GTNT composites. Figures $7(\mathrm{a})$ and $7(\mathrm{~b})$ show the nitrogen adsorptiondesorption isotherms and pore size distribution curves of the GTNT composites. The corresponding results of P25 powders are also present as the comparison. According to IUPAC classification, the GTNT composites exhibited a type IV isotherm of a type $\mathrm{H} 3$ hysteresis loop, typical of mesoporous materials [25]. The pore size distribution of the GTNT composites shows a bimodal size distribution, with the smaller sizes peaking at $1.5 \mathrm{~nm}$ and the larger sizes at $30 \mathrm{~nm}$, which is consist with the SEM and TEM results. The smaller mesopores can be related to the hollow structure of the titanate nanotubes, while larger mesopores would correspond to the spacing between of GO nanosheets and the gap between nanotubes. P25 also has two pore structures of $100 \mathrm{~nm}$ and $2 \mathrm{~nm}$, which may be caused by the agglomeration of P25. Although the GTNT composites and P25 have similar size distribution, the BET specific surface area differs a lot. The BET specific surface area of the GTNT composites and P25 is 236.9 and $46.0 \mathrm{~m}^{2} / \mathrm{g}$, respectively. Due to the advantages of abundant porous structure and high surface area, the GTNT composites would expect with excellent adsorption properties.

3.2. Adsorption Properties of the GTNT Composites. Kinetics experiment was first employed to determine the removal rate of $\mathrm{Co}(\mathrm{II})$ ions from water at initial concentration of $20 \mathrm{mg} / \mathrm{L}$. The adsorption kinetics of Co(II) on the GTNT composites is shown in Figure 8(a). As shown, in the first $10 \mathrm{~min}$, the adsorption of $\mathrm{Co}$ (II) on the GTNT composites happens rapidly, where almost $95 \%$ of the Co(II) ions can be adsorbed. Then, adsorption capacity gradually increased till it reached the equilibrium, where more than $98 \%$ of the contained Co(II) ions can be adsorbed. To further quantify the changes of $\mathrm{Co}$ (II) ions adsorption with time on the GTNT composites, the pseudo-first-order model (equation 1 [26]) and pseudo-second-order model (equation 2 [27]) are applied to simulate the adsorption kinetics process.

$$
\begin{aligned}
\ln q_{e}-q_{t} & =\ln q_{e}-k_{1} t, \\
\frac{t}{q_{t}} & =\frac{1}{k_{2} q_{e}^{2}}+\frac{t}{q_{e}},
\end{aligned}
$$

where $q_{e}$ and $q_{t}$ are the amounts of adsorbed fluoride $(\mathrm{mg} / \mathrm{g})$ at equilibrium and at any time $t(\mathrm{~min})$, respectively. $k_{1}$ $\left(\mathrm{min}^{-1}\right)$ and $k_{2}(\mathrm{~g} /(\mathrm{mg} \cdot \mathrm{min}))$ are the equilibrium rate constants for pseudo-first-order and pseudo-second-order sorptions, respectively.

Table 1 provides the fitting results of the experimental data fitted into pseudo-first-order and pseudo-secondorder models, respectively. Figure 8(b) shows the pseudosecond-order fitting of the experimental data. It can be seen that the regression coefficients $\left(R^{2}\right)$ of the pseudo- 


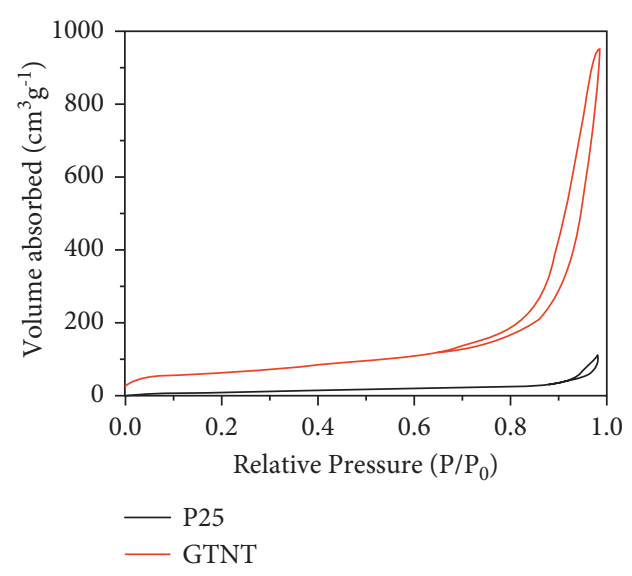

(a)

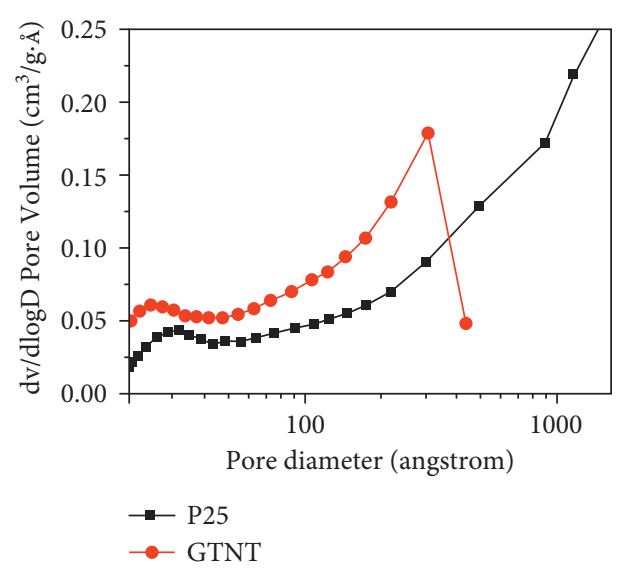

(b)

Figure 7: (a)-(b) The nitrogen adsorption-desorption isotherm and BJH pore size distribution curve of the GTNT composites and P25.

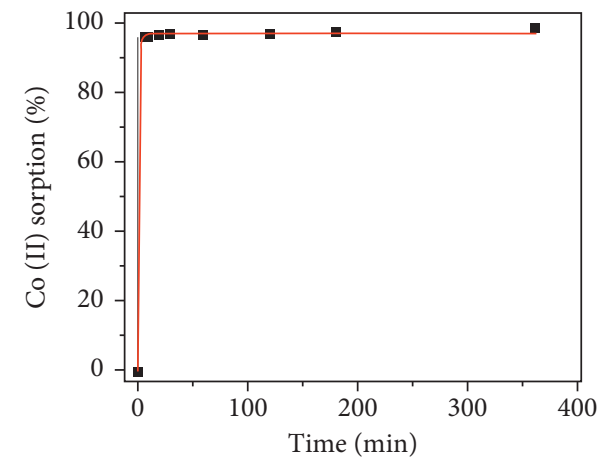

(a)

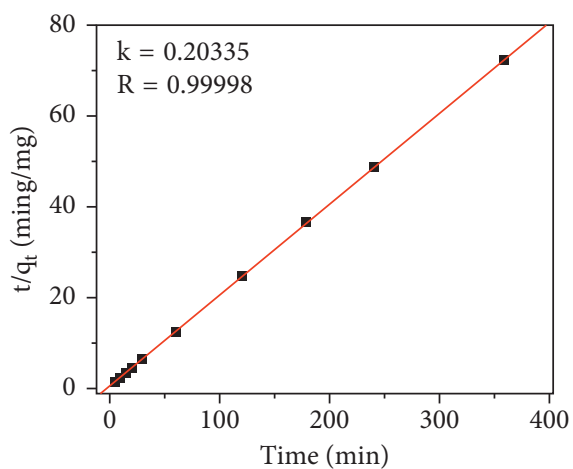

(b)

FIgURE 8: (a) Co(II) adsorption kinetics of the GTNT composites. (b) The corresponding pseudo-second-order fitting.

TABLE 1: Kinetics parameters for Co(II) ions adsorption on the GTNT composites.

\begin{tabular}{lcccccc}
\hline Equations & & \multicolumn{3}{c}{ First-order kinetics } & \multicolumn{3}{c}{ Second-order kinetics } \\
& & \multicolumn{3}{c}{$\ln \left(q_{e}-q_{t}\right)=\ln q_{e}-k_{1} t$} & & \multicolumn{2}{c}{$t / q_{t}=1 / k_{2} q_{e}^{2}+t / q_{e}$} \\
\hline$C_{o}(\mathrm{mg} / \mathrm{L})$ & $q_{e, \exp (\mathrm{mg} / \mathrm{g})}$ & $k_{1}(1 / \mathrm{min})$ & $q_{e, \mathrm{cal}}(\mathrm{mg} / \mathrm{g})$ & $R^{2}$ & $k_{2}(\mathrm{~g} /(\mathrm{mg} \cdot \mathrm{min}))$ & $q_{e, \mathrm{cal}}(\mathrm{mg} / \mathrm{g})$ \\
20 & 19.56 & 0.11 & 16.43 & 0.971 & 0.203 & $R^{2}$ \\
\hline
\end{tabular}

first-order model and pseudo-second-order model are 0.999 and 0.971 , respectively. The higher $R^{2}$ value indicates that the adsorption kinetic fitting of the GTNT composites favors the pseudo-second-order Co(II) removal process. The calculated equilibrium adsorption capacity $\left(q_{e}\right.$, cal $)$ is 19.85 when the initial Co(II) concentrations is $20 \mathrm{mg} / \mathrm{L}$, which is in agreement with experimental equilibrium adsorption capacities $\left(q_{e}, \exp \right)$.

The adsorption isotherm of $\mathrm{Co}(\mathrm{II})$ adsorption on the GTNT composites is also investigated, and the results are shown in Figure 9. Two commonly used isotherm models, namely, Langmuir and Freundlich were used in the present study for the data analysis $[28,29]$. Table 2 provides isotherm parameters computed from the Langmuir and Freundlich models. The higher $R^{2}$ value suggests that the Langmuir model presents better fitting for the adsorption data than the Freundlich model, implying that the adsorption of $\mathrm{Co}$ (II) on the GTNT composites is monolayer adsorption. The adsorption capacity of $\mathrm{Co}$ (II) on the GTNT composites is $211.1 \mathrm{mg} / \mathrm{g}$ when the equilibrium concentration is $88.9 \mathrm{mg} / \mathrm{L}$. The comparison of the $\mathrm{Co}$ (II) adsorption capacity of different adsorbents is given in Table 3. It can be seen that, compared with other adsorbents, the as-prepared GTNT composites exhibit the superior adsorption capacity. The good performance in $\mathrm{Co}$ (II) adsorption can be attributed to the benefit of the relative high surface area and hierarchical porous structure. The porous structure and relative high surface area can provide more active sites to trap $\mathrm{Co}$ (II) ions. The hierarchical structure not only provides sufficient diffusion channels for $\mathrm{Co}(\mathrm{II})$ ions but also avoids the 


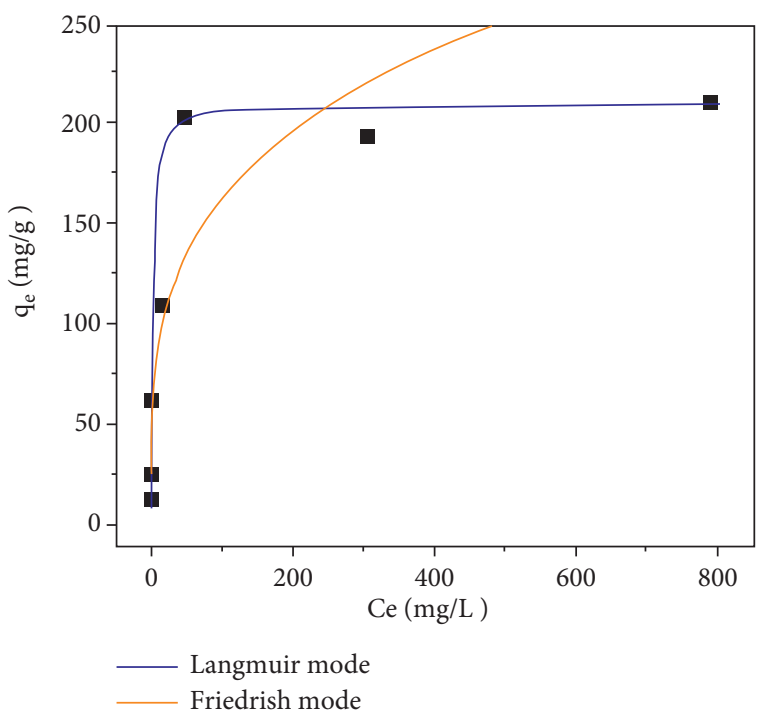

FIgURE 9: Adsorption isotherms of Co(II) ions on the GTNT composites and the corresponding Langmuir and Freundlich fitting.

Table 2: Langmuir and Freundlich adsorption isotherm parameters for $\mathrm{Co}(\mathrm{II})$ ions on the GTNT composites.

\begin{tabular}{lccccc}
\hline \multirow{2}{*}{ Equations } & & \multicolumn{2}{c}{ Langmuir model } & \multicolumn{2}{c}{ Freundlich model } \\
& & $q_{e}=q_{m} k_{L} C_{e} / 1+k_{L} C_{e}$ & \multicolumn{2}{c}{$q_{e}=k C_{e}^{1 / n}$} \\
\hline Parameter & $K_{\mathrm{L}}(\mathrm{L} / \mathrm{mg})$ & $q_{\max }(\mathrm{mg} / \mathrm{g})$ & $R^{2}$ & $n$ & $k$ \\
Values & 0.22 & 211.1 & 0.997 & 3.25 & 126.3 \\
\hline
\end{tabular}

TABle 3: The comparison of the Co(II) adsorption capacity of different adsorbents.

\begin{tabular}{lcc}
\hline Adsorbents & Adsorption capacity (mg/g) & References \\
\hline Hydroxyapatite & 20.92 & {$[30]$} \\
Poly-ortho aminophenol and glycerol & 117.9 & 68.2 \\
Graphene oxide & 156.9 & {$[31]$} \\
Layered titanates & 64.1 & {$[32]$} \\
Phosphate-modified magnetite@ferrihydrite & 66.7 & {$[33]$} \\
Sugarcane leaf biomass & 134.27 & {$[35]$} \\
Nanoscaled zero-valent iron/graphene composite & 211.1 & {$[36]$} \\
GTNT composite & Present work \\
\hline
\end{tabular}

aggregation of the titanate nanotubes. The combination effects enhanced the adsorption capacity of the GTNT composites.

The $\mathrm{pH}$ value of the wastewater is an important parameter in adsorption treatment technology, which would largely influence the adsorption processes. Thus, the effect of $\mathrm{pH}$ on $\mathrm{Co}$ (II) adsorption by the GTNT composites is studied in the $\mathrm{pH}$ ranging of 1.0-7.0, and results are shown in Figure 10 . At $\mathrm{pH}=7$, the equilibrium uptake of $\mathrm{Co}$ (II) ions is $243.2 \mathrm{mg} / \mathrm{g}$. The adsorption capacity of Co(II) on the GTNT composites quickly decreases with the decrease of $\mathrm{pH}$ value. The $\zeta$ potential of the GTNT composites at different $\mathrm{pH}$ is shown in Figure 11. With the decrease of $\mathrm{pH}$, the zeta potential of the GTNT composites continuously increases. The lower the $\mathrm{pH}$ value, the higher the zeta potential of the GTNT composites. In the $\mathrm{pH}$ range of 4.0-7.0, the GTNT composites are negative charged, while, when the $\mathrm{pH}$ value is lower than 4.0, the GTNT composites are positively charged.

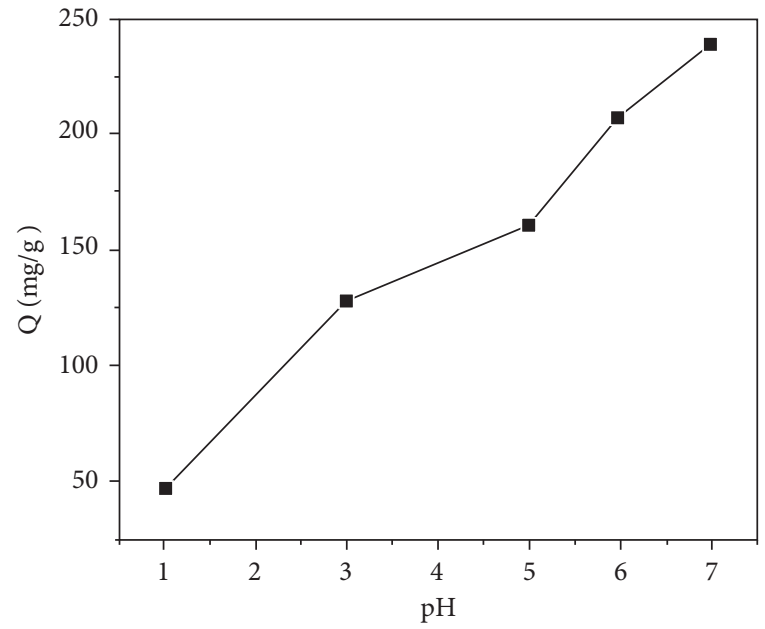

FIgURE 10: Effect of initial $\mathrm{pH}$ on Co(II) removal of the GTNT composites. 


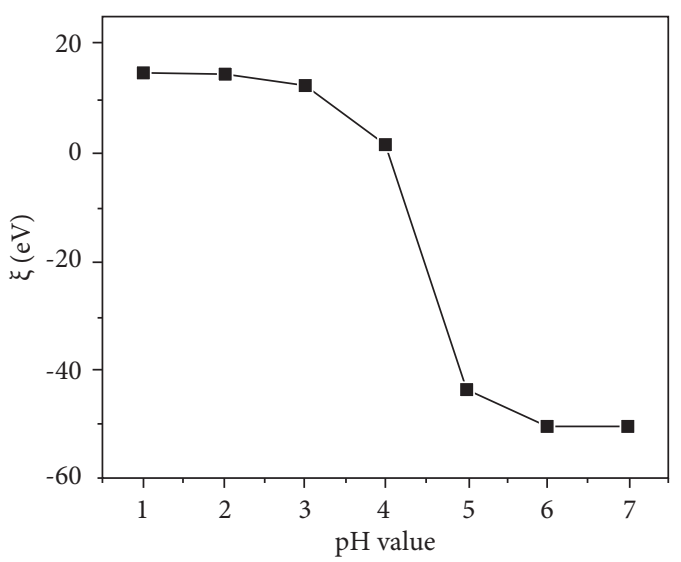

FIGURE 11: The zeta potential of the GTNT composites at different $\mathrm{pH}$.

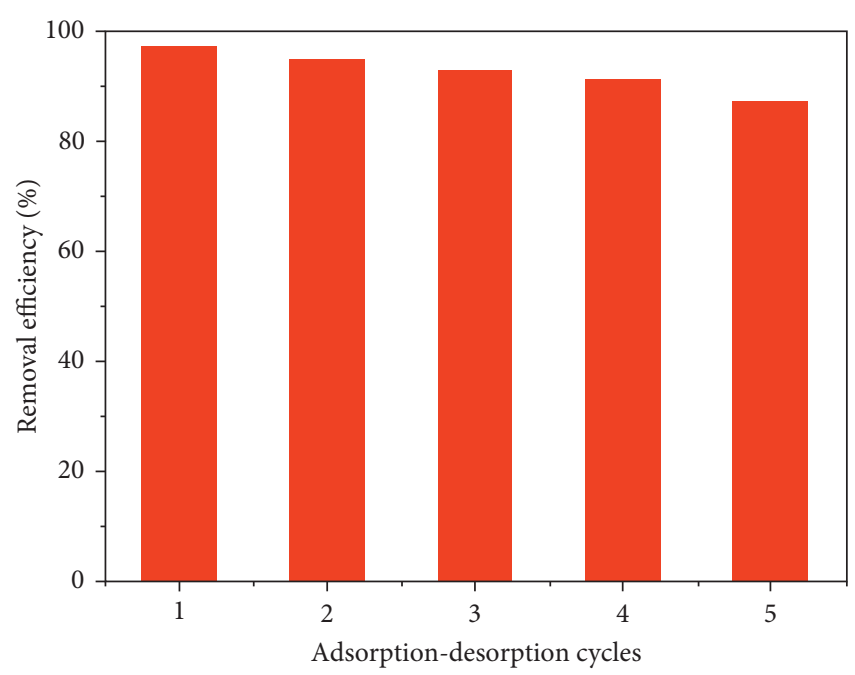

FIgURE 12: The Co(II) removal efficiency of the GTNT composites after 5 adsorption-desorption cycles.

$\mathrm{Co}$ (II) ion is a cation; thus, the higher negative charged on the surface of the GTNT composites, the greater its electrostatic attraction to $\mathrm{Co}(\mathrm{II})$ ions. Thus, the GTNT composites always exhibit better $\mathrm{Co}(\mathrm{II})$ adsorption performance under higher $\mathrm{pH}$ values.

The recycling experiment of GTNT composites was also investigated. The GTNT composites were recovered after the batch test and washed with dilute hydrochloric acid solution and then calcinated at $500^{\circ} \mathrm{C}$ for $2 \mathrm{~h}$ to get rid of adsorbed $\mathrm{Co}(\mathrm{II})$ ions. Figure 12 shows the Co(II) ions removal efficiency of the GTNT composites after 5 adsorption-desorption cycles. It can be found that, with the increase of reuse times, the performance of the GTNT composites decreases slightly; almost $87 \%$ Co(II) ions can be removal by GTNT composites after 5 adsorptiondesorption cycles. This decrease might be due to the blocking of some of the adsorption sites by $\mathrm{Co}(\mathrm{II})$ ions.

In common condition, many kinds of polluted metal ions often coexist in the wastewater; thus, the interference of coexisting ions on $\mathrm{Co}$ (II) adsorption performance of the GTNT composites are studied. As shown in Figure 13, it can be found that $\mathrm{Na}^{+}, \mathrm{K}^{+}$, and $\mathrm{Mg}^{2+}$ ions have shown a

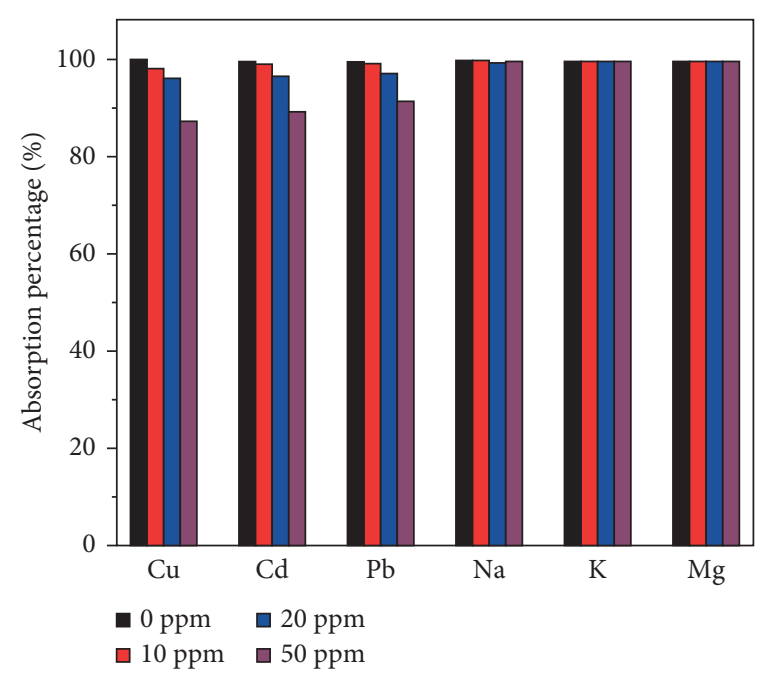

Figure 13: Effect of the competing anions on the GTNT composites.

negligible effect on the Co(II) adsorption of the GTNT composites. However, when $\mathrm{Cu}^{2+}, \mathrm{Cd}^{2+}$, and $\mathrm{Pb}^{2+}$ ions exist in the system, the interference can be clearly observed on the $\mathrm{Co}$ (II) adsorption of the GTNT composites. The greater the ionic strength, the more significant the effect, which may be attributed to the ions' competition for active sites.

\section{Conclusion}

In summary, a novel GO/titanate nanotubes (GTNT) composite was synthesized through a facile alkaline hydrothermal method. The specific surface area of the GTNT composites is $236.9 \mathrm{~m}^{2} / \mathrm{g}$, and the large surface area is beneficial to removal $\mathrm{Co}$ (II) from the radioactive wastewater. The batch adsorption experiments demonstrated that the GTNT composites have high adsorption capacity and rapid kinetics for $\mathrm{Co}(\mathrm{II})$ adsorption (10 min for equilibrium). The adsorption capacity of the GTNT composites is $211.1 \mathrm{mg} / \mathrm{g}$. The adsorption kinetics of the GTNT composites fits well to the pseudo-second-order model, while the adsorption isotherm of which fits well to the Langmuir model. The adsorption performance of $\mathrm{Co}(\mathrm{II})$ ions on the GTNT composites has a great relationship with the $\mathrm{pH}$ value, and in the $\mathrm{pH}$ range of $1-7$, the $\mathrm{Co}(\mathrm{II})$ adsorption capacity of the GTNT composites greatly increases with the increase of the $\mathrm{pH}$ value. In addition, the effect of coexisting anions on fluoride removal is also investigated. $\mathrm{Na}^{+}, \mathrm{K}^{+}$, and $\mathrm{Mg}^{2+}$ ions have shown a negligible effect on the Co(II) adsorption efficiency of the GTNT composites. However, the existences of $\mathrm{Cu}^{2+}, \mathrm{Cd}^{2+}$, and $\mathrm{Pb}^{2+}$ ions would clearly have an effect on the Co(II) adsorption of the GTNT composites. The adsorption mechanism is also discussed. Thus, the GTNT composites can be considered as the potential functional material for removing the radioactive metals contained wastewater.

\section{Data Availability}

No data were used to support this study. 


\section{Conflicts of Interest}

The authors declare that they have no conflicts of interest.

\section{Authors' Contributions}

Min-Da Xu and Zhen Jin contributed equally to this work.

\section{Acknowledgments}

The authors gratefully acknowledge the financial support provided by the National Key Research and Development Program (2019YFC0408504), Natural Science Foundation of Anhui Province (2008085MB44), Natural Science Research Project of Anhui Educational Committee (KJ2019A0772 and KJ2018ZD048), Initial Scientific Research Fund of Anhui Jianzhu University (2017QD14), and Science and Technology Service Network Initiative of the Chinese Academy of Sciences (KFJ-STS-QYZD-173).

\section{References}

[1] Y. Li, G. Zou, S. Yang et al., "Integration of bio-inspired adsorption and photodegradation for the treatment of organicscontaining radioactive wastewater," Chemical Engineering Journal, vol. 364, pp. 139-145, 2019.

[2] X. Zhang and Y. Liu, "Ultrafast removal of radioactive strontium ions from contaminated water by nanostructured layered sodium vanadosilicate with high adsorption capacity and selectivity," Journal of Hazardous Materials, vol. 398, Article ID 122907, 2020.

[3] K. Chen, C. Chen, X. Ren, A. Alsaedi, and T. Hayat, "Interaction mechanism between different facet $\mathrm{TiO} 2$ and $\mathrm{U}(\mathrm{VI})$ : experimental and density-functional theory investigation," Chemical Engineering Journal, vol. 359, pp. 944-954, 2019.

[4] W. Luo, J. T. Chen, H. T. Lin, and X. X. Ye, "Biomass base membrane with phenol hydroxy-amino group for ultraselective adsorption of radioactive $\mathrm{Co}$ (II) in trace concentration," Separation and Purification Technology, vol. 272, 2021.

[5] C. Liu, D. Zhao, K. Zhang et al., "Fabrication of Si/Ti-based amino-functionalized hybrids and their adsorption towards cobalt(II)," Journal of Molecular Liquids, vol. 289, 2019.

[6] M. Liu, C. Chen, J. Hu, X. Wu, and X. Wang, "Synthesis of magnetite/graphene oxide composite and application for cobalt(II) removal," Journal of Physical Chemistry C, vol. 115, no. 51, pp. 25234-25240, 2011.

[7] S. Achour, S. Amokrane, S. Chegrouche, B. Guedioura, and D. Nibou, "Adsorption mechanism study of radionuclide Co60 by purified and alpha- $\mathrm{Fe}_{2} \mathrm{O}_{3}$-supported bentonite from radioactive solution," Arabian Journal for Science and Engineering, vol. 46, 2021.

[8] H.-K. Lee, J.-W. Choi, and S.-J. Choi, "Magnetic ionimprinted polymer based on mesoporous silica for selective removal of Co(II) from radioactive wastewater," Separation Science and Technology, vol. 56, no. 11, pp. 1842-1852, 2021.

[9] M. M. Gouda, Y. H. Dawood, A. A. Zaki, H. A. S. Ibrahim, M. R. El-Naggar, and A. Gad, "Adsorption characteristic of $\mathrm{Cs}+$ and $\mathrm{Co} 2+$ ions from aqueous solutions onto geological sediments of radioactive waste disposal site," Journal of Geochemical Exploration, vol. 206, Article ID 106366, 2019.
[10] M. Safdar, S. Mustafa, A. Naeem et al., "Effect of sorption on Co (II), Cu (II), Ni (II) and $\mathrm{Zn}$ (II) ions precipitation," Desalination, vol. 266, no. 1-3, pp. 171-174, 2011.

[11] Z. Ren, W. Zhang, H. Meng, J. Liu, and S. Wang, "Extraction separation of $\mathrm{Cu}(\mathrm{II})$ and $\mathrm{Co}(\mathrm{II})$ from sulfuric solutions by hollow fiber renewal liquid membrane," Journal of Membrane Science, vol. 365, no. 1-2, pp. 260-268, 2010.

[12] L. Jiang, L. Huang, and Y. Sun, "Recovery of flakey cobalt from aqueous $\mathrm{Co}$ (II) with simultaneous hydrogen production in microbial electrolysis cells," International Journal of Hydrogen Energy, vol. 39, no. 2, pp. 654-663, 2014.

[13] A. A. Beni, A. Esmaeili, and Y. Behjat, "Invent of a simultaneous adsorption and separation process based on dynamic membrane for treatment $\mathrm{Zn}(\mathrm{II}), \mathrm{Ni}(\mathrm{II})$ and, $\mathrm{Co}(\mathrm{II})$ industrial wastewater," Arabian Journal of Chemistry, vol. 14, 2021.

[14] Z. Jin, Y. Luo, T. Jia et al., "Efficient removal of fluoride by hierarchical $\mathrm{MgO}$ microspheres: performance and mechanism study," Applied Surface Science, vol. 357, pp. 1080-1088, 2015.

[15] E. Demirbas, “Adsorption of cobalt(II) ions from aqueous solution onto activated carbon prepared from hazelnut shells," Adsorption Science and Technology, vol. 21, pp. 951963, 2003.

[16] G. M. Rashad, M. R. Mahmoud, A. M. Elewa, E. Metwally, and E. A. Saad, "Removal of radiocobalt from aqueous solutions by adsorption onto low-cost adsorbents," Journal of Radioanalytical and Nuclear Chemistry, vol. 309, no. 3, pp. 10651076, 2016.

[17] O. K. Alduaij, M. I. Attia, L. Khezami, and K. K. Taha, "Removal of cobalt(Ii) from aqueous solution by local Saudi bentonite: kinetic and equilibrium investigations," Macedonian Journal of Chemistry and Chemical Engineering, vol. 35, no. 1, pp. 87-96, 2016.

[18] G. Sheng, S. Yang, J. Sheng, D. Zhao, and X. Wang, "Influence of solution chemistry on the removal of $\mathrm{Ni}$ (II) from aqueous solution to titanate nanotubes," Chemical Engineering Journal, vol. 168, no. 1, pp. 178-182, 2011.

[19] T. Wang, W. Liu, L. Xiong, N. Xu, and J. Ni, "Influence of pH, ionic strength and humic acid on competitive adsorption of $\mathrm{Pb}(\mathrm{II}), \mathrm{Cd}(\mathrm{II})$ and $\mathrm{Cr}(\mathrm{III})$ onto titanate nanotubes," Chemical Engineering Journal, vol. 215-216, pp. 366-374, 2013.

[20] S. Wu, K. Zhang, X. Wang et al., "Enhanced adsorption of cadmium ions by 3D sulfonated reduced graphene oxide," Chemical Engineering Journal, vol. 262, pp. 1292-1302, 2015.

[21] G. Zhao, X. Ren, X. Gao et al., "Removal of $\mathrm{Pb}$ (II) ions from aqueous solutions on few-layered graphene oxide nanosheets," Dalton Transactions, vol. 40, no. 41, pp. 10945-10952, 2011.

[22] X. Yang, X. Zhang, Y. Ma, Y. Huang, Y. Wang, and Y. Chen, "Superparamagnetic graphene oxide-Fe3O4 nanoparticles hybrid for controlled targeted drug carriers," Journal of Materials Chemistry, vol. 19, no. 18, pp. 2710-2714, 2009.

[23] Z.-Q. Zhao, X. Chen, Q. Yang, J.-H. Liu, and X.-J. Huang, "Selective adsorption toward toxic metal ions results in selective response: electrochemical studies on a polypyrrole/ reduced graphene oxide nanocomposite," Chemical Communications, vol. 48, no. 16, pp. 2180-2182, 2012.

[24] Y. D. Li and X. M. Sun, "Synthesis and characterization of ionexchangeable titanate nanotubes," Chemistry-A European Journal, vol. 9, pp. 2229-2238, 2003.

[25] Z. Jin, F.-L. Meng, Y. Jia et al., "Porous $\mathrm{TiO} 2$ nanowires derived from nanotubes: synthesis, characterzation and their enhanced photocatalytic properties," Microporous and Mesoporous Materials, vol. 181, pp. 146-153, 2013. 
[26] S. Lagergren, "About the theory of so-called adsorption of soluble substances," Kungliga Svenska Vetenskapsakademiens Handlingar, vol. 24, pp. 1-39, 1898.

[27] Y.-S. Ho, "Second-order kinetic model for the sorption of cadmium onto tree fern: a comparison of linear and nonlinear methods," Water Research, vol. 40, no. 1, pp. 119-125, 2006.

[28] I. Langmuir, "The constitution and fundamental properties of solids and liquids. Part I. Solids," Journal of the American Chemical Society, vol. 38, no. 11, pp. 2221-2295, 1916.

[29] H. Freundlich, "Concerning adsorption in solutions," Zeitschrift fur Physikalische Chemie-Stochiometrie und Verwandtschaftslehre, vol. 57, pp. 385-470, 1906.

[30] I. Smiciklas, S. Dimovic, I. Plecas, and M. Mitric, "Removal of $\mathrm{Co} 2+$ from aqueous solutions by hydroxyapatite," Water Research, vol. 40, pp. 2267-2274, 2006.

[31] A. Abdelfatah, O. F. Abdel-Gawad, A. M. Elzanaty, A. M. Rabie, and F. Mohamed, "Fabrication and optimization of poly(ortho-aminophenol) doped glycerol for efficient removal of cobalt ion from wastewater," Journal of Molecular Liquids, vol. 345, Article ID 117034, 2021.

[32] G. Zhao, J. Li, X. Ren, C. Chen, and X. Wang, "Few-layered graphene oxide nanosheets as superior sorbents for heavy metal ion pollution management," Environmental Science and Technology, vol. 45, no. 24, pp. 10454-10462, 2011.

[33] V. d. A. Cardoso, A. G. d. Souza, P. P. C. Sartoratto, and L. M. Nunes, "The ionic exchange process of cobalt, nickel and copper(II) in alkaline and acid-layered titanates," Colloids and Surfaces A: Physicochemical and Engineering Aspects, vol. 248, no. 1-3, pp. 145-149, 2004.

[34] H. Fu, H. He, R. Zhu, L. Ling, W. Zhang, and Q. Chen, "Phosphate modified magnetite@ferrihydrite as an magnetic adsorbent for $\mathrm{Cd}(\mathrm{II})$ removal from water, soil, and sediment," The Science of the Total Environment, vol. 764, Article ID 142846, 2021.

[35] O. A. Adigun, V. O. Oninla, N. A. A. Babarinde, K. O. Oyedotun, and N. Manyala, "Characterization of sugarcane leaf-biomass and investigation of its efficiency in removing Nickel(II), Chromium(III) and Cobalt(II) ions from polluted water," Surfaces and Interfaces, vol. 20, 2020.

[36] M. Xing and J. Wang, "Nanoscaled zero valent iron/graphene composite as an efficient adsorbent for $\mathrm{Co}$ (II) removal from aqueous solution," Journal of Colloid and Interface Science, vol. 474, pp. 119-128, 2016. 